\title{
LANDSLIDES DURING THE EARTHQUAKES ON MAY 26 AND JULY 26, 2003 IN MIYAGI, JAPAN
}

\author{
Ryosuke Uzuoka ${ }^{\text {i) }}$, Noriaki Sento ${ }^{\mathrm{i})}$, Motoki KAZAma ${ }^{\mathrm{i})}$ and Toshiyasu UnNo ${ }^{\mathrm{i})}$
}

\begin{abstract}
We conducted a site investigation for two major landslides: Dateshita landslide, Tsukidate-cho during the earthquake on May 26, 2003; and Nishisaruta landslide, Kanan-cho during the earthquake on July 26, 2003. In addition, we examined physical and mechanical soil properties and performed preliminary numerical simulations. The subsurface soil of the gentle slope of Dateshita landslide with an angle of about $7^{\circ}$ was a fill with pyroclastic sediments. The structure of the fill was very loose, but the unsaturated soil remained stable with high suction. The landslide occurred during or immediately after the principle motion of the earthquake. The slide mass behaved as a mudflow. Then the collapsed soil easily fluidized with cyclic shear. It is likely that the saturated fill liquefied during the earthquake. Moreover, it is possible that the unsaturated fill fluidized, losing the initial shear strength during cyclic shear induced by the earthquake. The Nishisaruta landslide with similar magnitude and configuration to the Dateshita landslide occurred a few minutes after the principle motion of the main shock. Rainfall was an important feature that exacerbated the Nishisaruta landslide, whereas no rainfall had been observed for a week before the Dateshita landslide. The subsurface soil of slope of the Nishisaruta landslide was a fill with fine-graded sand, which originated from sandstone on the hill. The upper portion of the slope that lost shear strength because of liquefaction descended along the slope, and spread with high water content on the lower rice field. Numerical simulations have suggested that the saturated fill liquefied during the main shock. Residual excess pore pressure induced by the foreshock affected the slope's stability.
\end{abstract}

Key words: earthquake, landslide, liquefaction, numerical analysis, site investigation, slope stability (IGC: C0/E8)

\section{INTRODUCTION}

Two disastrous earthquakes hit the northeastern area of Honshu Island of Japan-the Tohoku area. The locations of epicenters of the two earthquakes are shown in Fig. 1. The first earthquake occurred in the Pacific Plate with the epicenter off the coast of Miyagi Prefecture at 18:24, local time on 26 May, 2003. We will call the earthquake "526 Eq." hereafter. The National Research Institute for Earth Science and Disaster Prevention (NIED) assigned a moment magnitude (Mw) of 7.0 to this earthquake, with focal depth of about $70 \mathrm{~km}$. The second earthquake occurred at an inland north area of Miyagi Prefecture at 7:13, local time, on 26 July, 2003, just two months after the $526 \mathrm{Eq}$. We will call this earthquake "726 Eq." hereafter. The NIED assigned Mw of 6.1 to this earthquake, with about $12.9-\mathrm{km}$ focal depth. In addition, a large foreshock and aftershock with slightly smaller magnitudes than the main shock occurred at 0:13 and 16:56, respectively, on the same day. The respective epicenters of these three shocks are located around the Asahiyama Hill. The NIED assigned Mw of 5.5 and focal depth of $12.8 \mathrm{~km}$ to the foreshock, and $\mathrm{Mw}$ of 5.3 and focal depth of $13.3 \mathrm{~km}$ to the aftershock. It was remarka- ble that three large earthquakes hit this limited area within a day. Many strong motion records for these events were observed by NIED, JMA (Japan Meteorological Agency), MLIT (Ministry of Land, Infrastructure and Transport), and other organizations. Peak acceleration of over $1 \mathrm{G}$ was recorded at some observation sites.

These earthquakes caused severe damage to the infrastructure and buildings, and injured several hundred people. The 526 Eq. caused extensive damage over a wide area of Miyagi and Iwate Prefectures. More than 2,000 houses in the prefectures were partially collapsed. Reinforced concrete piers of the Tohoku express railway over $100 \mathrm{~km}$ apart from the epicenter were partially damaged. The 726 Eq., on the other hand, caused intensive damage in a relatively small area of Miyagi Prefecture. More than 1,000 houses had totally collapsed and more than 10,000 houses had partially collapsed. Some reinforced buildings, hospitals and schools, were severely damaged. Many road embankments and river dikes deformed and settled by over $1 \mathrm{~m}$ at some locations.

Geotechnical hazards such as liquefaction, rock falls and landslides including small slope failures were observed during the events. Sites at which we found traces of sand boil after the $526 \mathrm{Eq}$, spread along the

i) Dept. of Civil Engineering, Graduate School of Engineering, Tohoku University, Japan (unno@soill.civil.tohoku.ac.jp).

The manuscript for this paper was received for review on June 14, 2004; approved on March 11, 2005.

Written discussions on this paper should be submitted before March 1, 2006 to the Japanese Geotechnical Society, 4-38-2, Sengoku, Bunkyo$\mathrm{ku}$, Tokyo 112-0011, Japan. Upon request the closing date may be extended one month. 


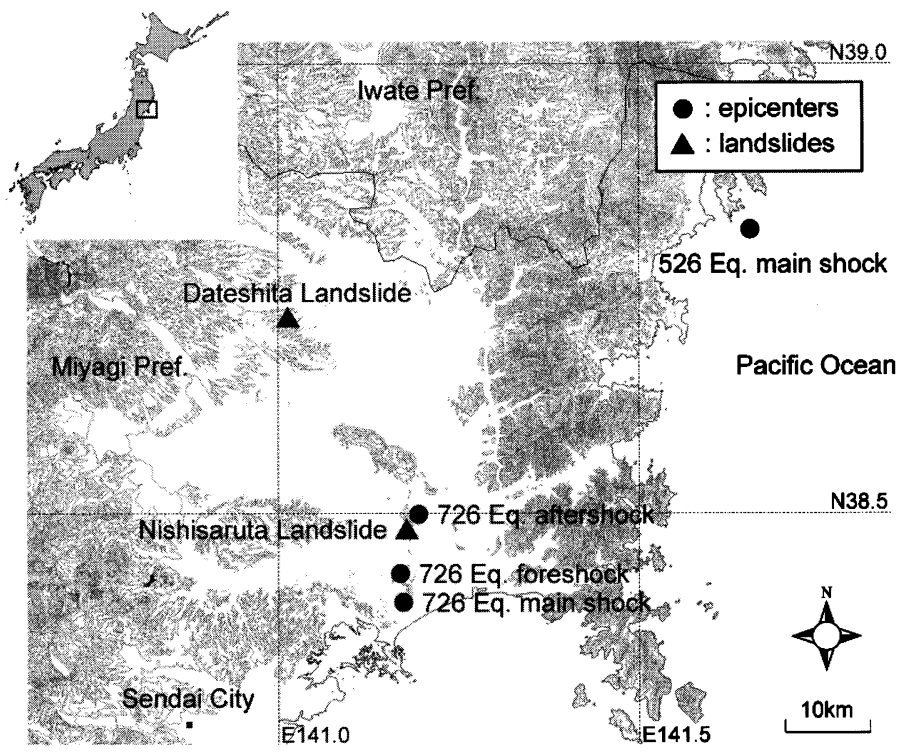

Fig. 1. Locations of major landslides and epicenters of the $526 \mathrm{Eq}$. and 726 Eq. (epicenters by Japan Meteorological Agency)

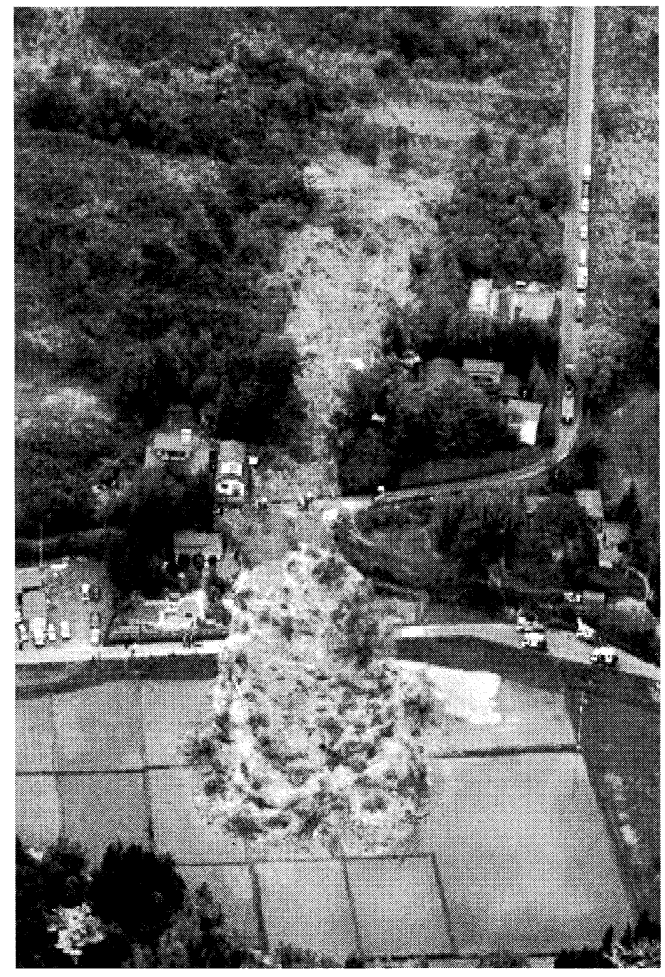

Photo 1. Aerial view of Dateshita landslide, Tsukidate-cho after the 526 Eq. (courtesy of Kokusai Kogyo Co., Ltd.)

coast. Traces of sand boil at some sites after the $726 \mathrm{Eq}$. were observed at the same places that were liquefied during the $526 \mathrm{Eq}$. Rock failures during the $526 \mathrm{Eq}$. were observed extensively around the mountain area. Some public roadways were closed temporarily. The largest landslide induced by the $526 \mathrm{Eq}$. was the Dateshita landslide in Tsukidate-cho in northern Miyagi. The muddy collapsed soil flowed from a very gentle slope, as shown in Photo 1. The site was situated about $60 \mathrm{~km}$

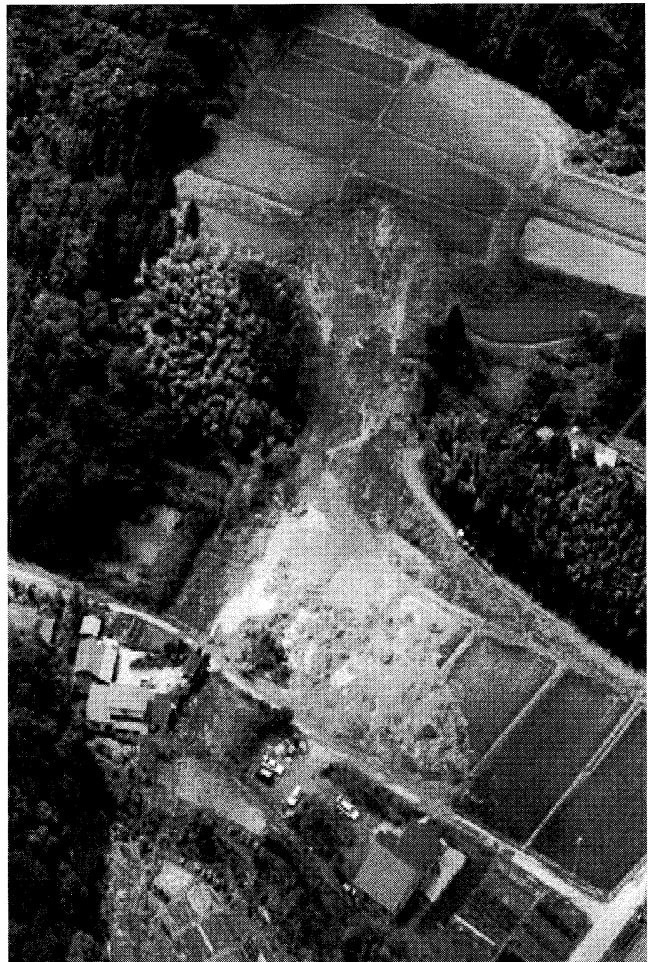

Photo 2. Aerial view of Nishisaruta landslide, Kanan-cho after the 726 Eq. (courtesy of Kokusai Kogyo Co., Ltd.)

away from the epicenter, as shown in Fig. 1. More than 180 landslides, slope failures and rock failures occurred around the Asahiyama Hill during the 726 Eq. (Irisawa, 2003). A landslide with similar magnitude and configuration to the Dateshita landslide occurred after the main shock at Nishisaruta, Kanan-cho, as shown in Photo 2. The Nishisaruta landslide, on the other hand, was very close to the source area of the earthquake as shown in Fig. 1. Although the angle of the original slope was 


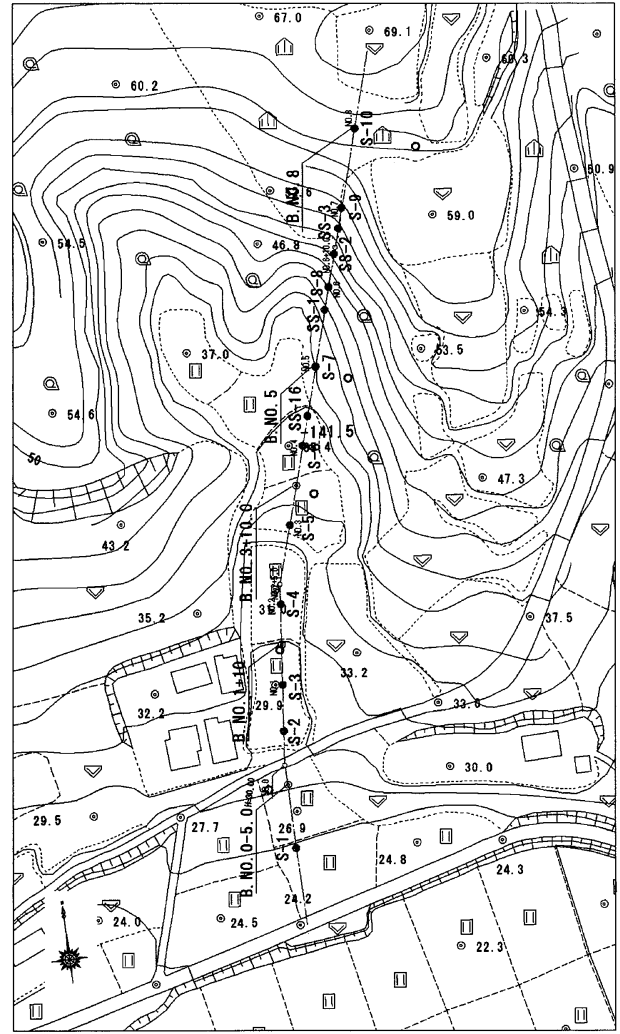

(a) Before filling in 1970's

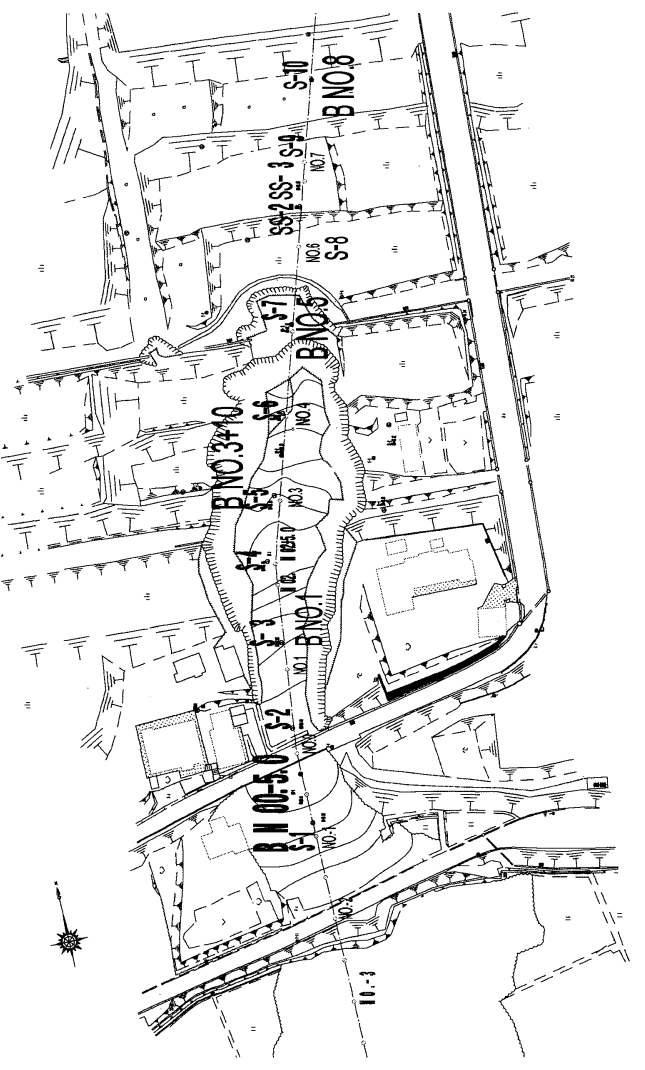

(b) After filling and failure in 2003

Fig. 2. Topography and collapsed configuration of Dateshita landslide (courtesy of Miyagi Prefectural Government)

steeper than that of Dateshita landslide, the average slope angle was less than $30^{\circ}$.

Fortunately however, these landslides resulted in no deaths. Recent earthquake-induced landslides have caused serious structural damages and heavy casualties. The Nikawa landslide was a large landslide disaster caused by the Hyogo-ken Nanbu earthquake in 1995. The landslide destroyed 11 houses and killed 34 people. The soil-mass volume was ca. $110,000 \mathrm{~m}^{3}$; the distance traveled was about $175 \mathrm{~m}$ (Sassa et al., 1996). The Las Colinas landslide in the $2001 \mathrm{El}$ Salvador earthquake was the most tragic. A huge soil mass (ca. 200,000 $\mathrm{m}^{3}$ ) was thrown from the rim of a mountain ridge rising behind Nueva San Salvador. It inundated and crushed hundreds of homes, consequently killing more than 500 people (Konagai et al., 2002). Considering the above disasters, we must clarify the mechanisms and influences of landslides, and leave records of landslides because prediction of occurrence and travel distance of earthquake-induced landslides is difficult.

The authors performed site investigation for two major landslides - the Dateshita landslide during the $526 \mathrm{Eq}$. and the Nishisaruta landslide during the 726 Eq.-after each earthquake. This report describes the site investigation results. It mentions some results of laboratory tests using soil samples and numerical simulations to discuss possible failure mechanisms of the two landslides.

\section{LANDSLIDE AT DATESHITA, TSUKIDATE-CHO DURING THE MAY 262003 EARTHQUAKE}

\section{Slide Overview}

Large flow failure of a gentle artificial slope occurred at Dateshita, Tsukidate-cho during the $526 \mathrm{Eq}$. The averaged original slope angle of about $7^{\circ}$ was very gentle, as shown in Photo 1. The collapsed portion was about $40 \mathrm{~m}$ wide and $80 \mathrm{~m}$ long, with a depth of about $5 \mathrm{~m}$. It deposited about $50 \mathrm{~m}$ wide and $120 \mathrm{~m}$ long at downstream side. It is estimated that the volume of the collapsed soil was about $8,100 \mathrm{~m}^{3}$. The uppermost scarp of the collapsed slope was about $25 \mathrm{~m}$ high and $180 \mathrm{~m}$ long from the lowermost deposits on a rice field. The mudflow destroyed some houses along its way, fortunately killing no one.

\section{Site Geology and Topography}

The surface soil of a hill behind the slide consists mainly of pyroclastic sediments-pumice tuff without clear stratification. The origin of the sediments is estimated to be a part of the Onikoube pyroclastic flow which occurred about one million years ago. The collapsed area is located on a plant field that was filled with surrounding sediments in the 1970s. Figure 2 presents a comparison of the original topography before the filling with the present topography of the collapsed part. This comparison indicates that the collapsed area at the 


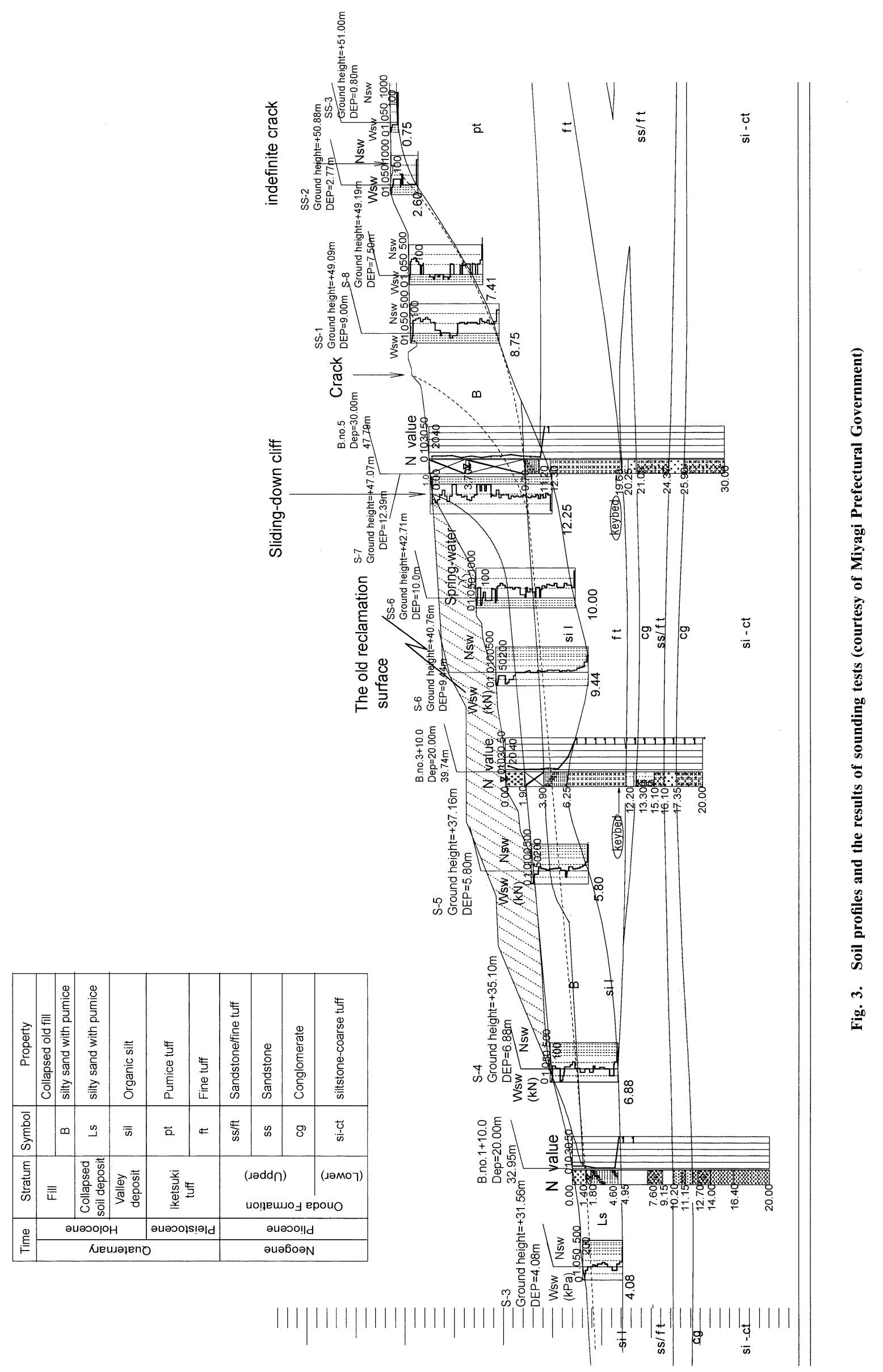




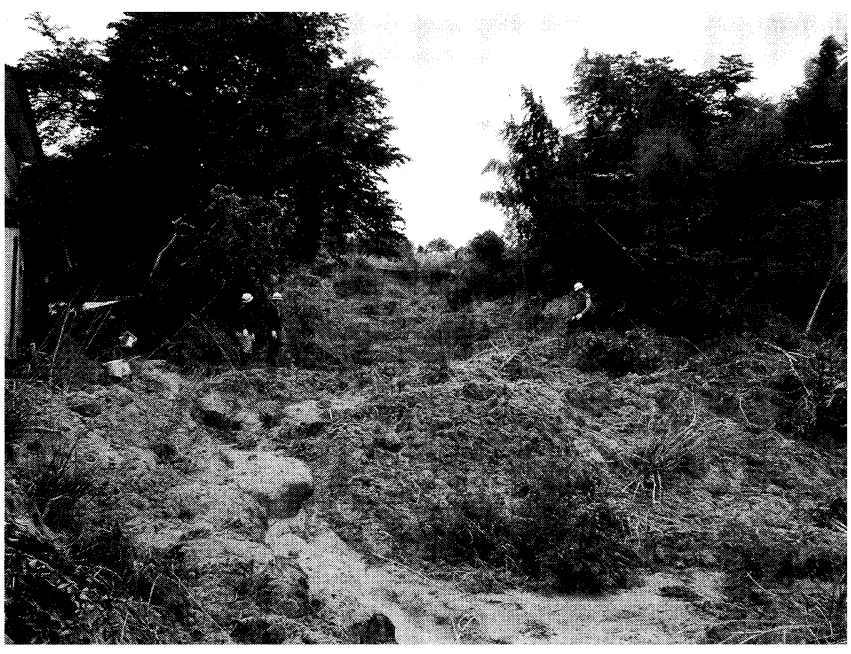

Photo 3. Collapsed soil and trace of mudflow in the lower part of the photo at the upstream side of the slide, right side of houses on May 27 (courtesy of Dr. Motoyuki Ushiyama)

present topography coincides with the location of a valley in the original topography. This fact is understood because there was a small pond that retains spring water at S-2 in Fig. 2, at the eastern side of the houses at the lower edge of the collapsed area. The uppermost portion of the scarp was close to the ridge of the hill; no clear water source except for rain was found around the ridge.

Figure 3 shows the soil profiles and results of sounding tests, standard penetration tests, and Swedish sounding tests, along the longitudinal section of the collapsed portion. The collapsed portion of the fill was about 5-m thick in maximum. Under the failure plane, a noncollapsed fill with thickness of about 2-3 m remained; it was underlain with organic sandy silt and tuff layers. The $\mathrm{N}$ value of the remaining fill was about 1 blow. Therefore, the filling soil was inferred to be very soft. The ground water level was about GL-3 $\mathrm{m}$ behind the uppermost scarp; it was the ground level at the center of failure plane, at boring No. 3. The present ground water level suggests that the fill layer with thickness of a few meters from the surface was estimated to be unsaturated during the earthquake because it had not rained for a week before the earthquake. Furthermore, the bottom of the collapsed portion was possibly saturated during the earthquake.

\section{Detailed Features and Possible Motion of the Slide}

Detailed features of the slide revealed that the landslide behaved as a mudflow. Photo 3 shows collapsed soil at the upstream side of the slide on the following day. A trace of the mudflow in the lower part of the photo is observable, even though it had not rained for 4 days subsequent to the earthquake. Therefore, the collapsed soil possibly contained much water.

Traces of mud splashes were observed at some places. Photo 4 shows traces of mud splashes remaining on the wall of the house at the western side of the slide. Other traces of mud splashes with height of about $2 \mathrm{~m}$ were

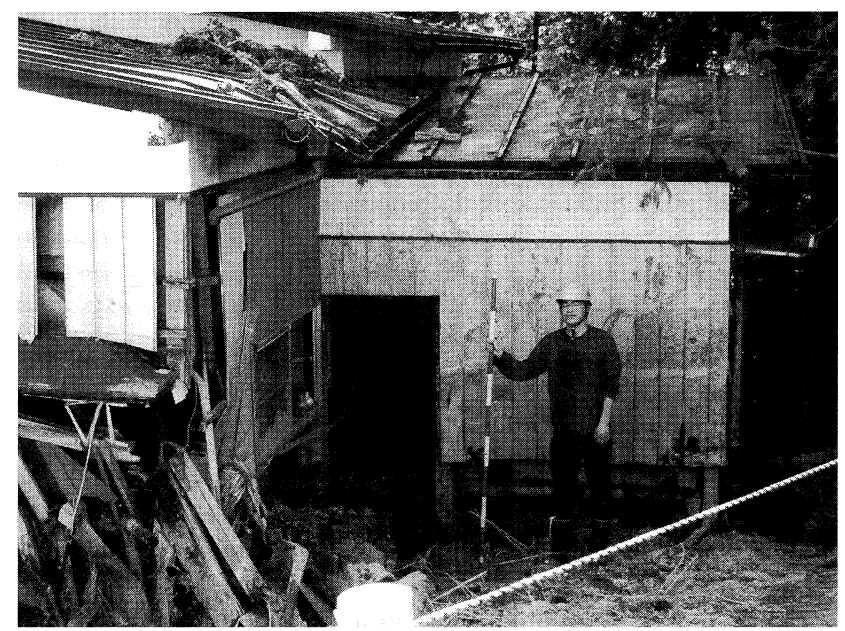

Photo 4. Traces of mud splashes remaining on the wall of house at the west side of the slide on May 29

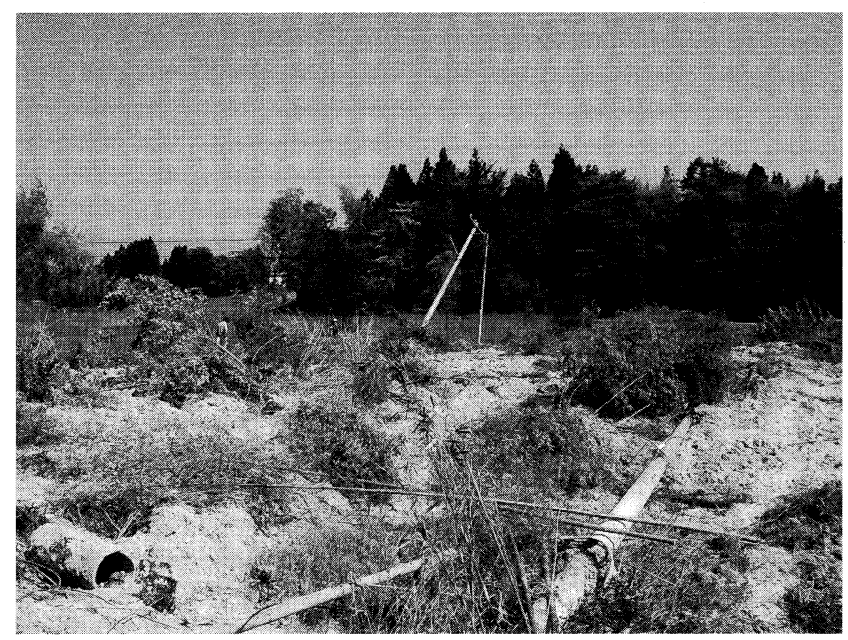

Photo 5. Collapsed soil deposit, flushed electronic poles and sewage pipes at the downstream side of the slide, west side on rice field on May 29

observed on the trees along the landslide and on the bamboo on a rice field. The traces evidenced that the flow speed of the landslide was not slow. In fact, a witness who lived in a house beside the slide said: "After the shaking intensity became stronger, I watched the slope movement through a window. The mass of collapsed soil snaked along the slope down to my house. My wife, who left the house immediately after the shaking, was buried to the waist." Another witness who lived in the house that was broken by the slide also said: "After the shaking intensified, a propane tank that was set outside the house wall, shot into the house, breaking the wall with mud; a supporting column of the house sounded as though it had broken. Then, I got out of the house after shutting off the electricity. It took about 60-90 seconds from the beginning of the shaking. An electric pole, located on the north side of the house before the earthquake, had moved south, a distance of about $5 \mathrm{~m}$. The collapsed soil had 


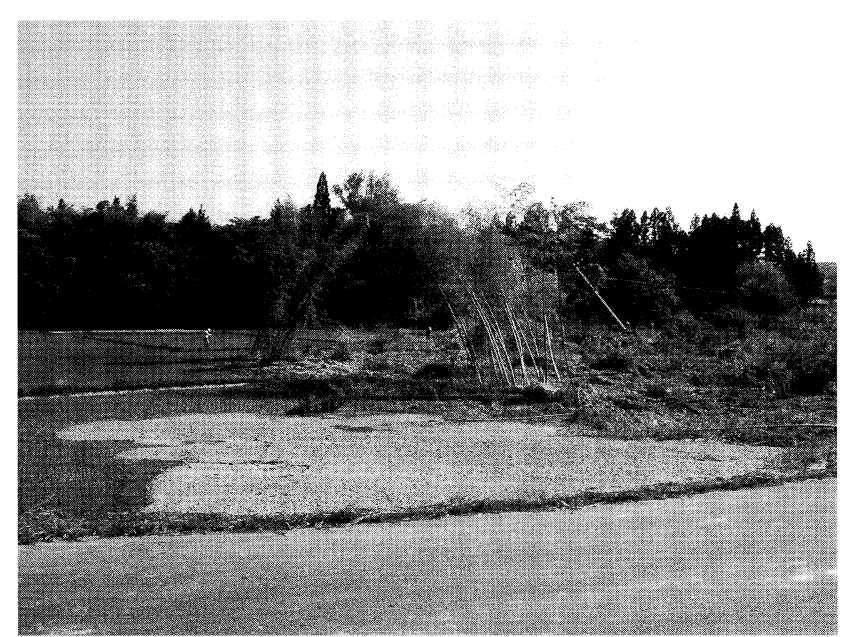

Photo 6. Collapsed soil deposit, flushed bamboos remaining standing and pumice deposit flown out the slide in the lower part of the photo at the downstream side of the slide, east side on rice field on May 29

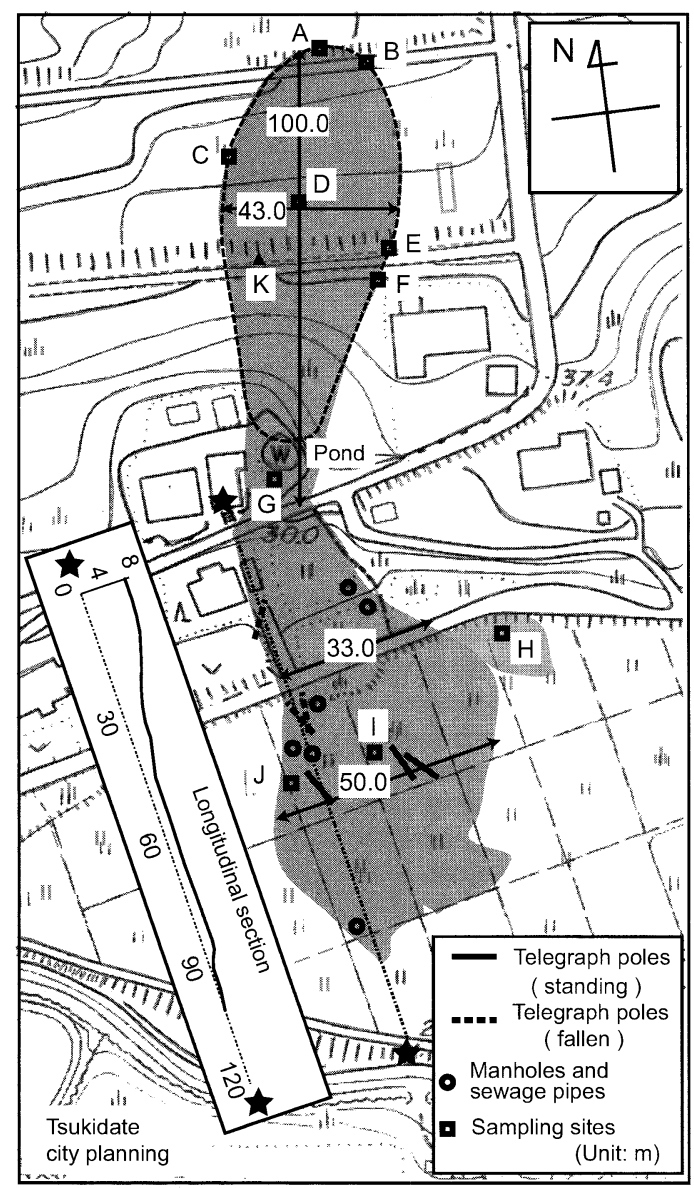

Fig. 4. Configuration of collapsed soil and locations of sampling site

spread on a rice field. Bamboo stands, located on the north side of the road at the north side of the house, had moved to the rice field." These accounts clarify that the slide traveled a distance of about 120-180 m over about 60-90 seconds. Therefore, the averaged velocity is estimated to be about $1.3-3.0 \mathrm{~m} / \mathrm{s}$. Konagai (2003) also suggested that the velocity at the center of the stream

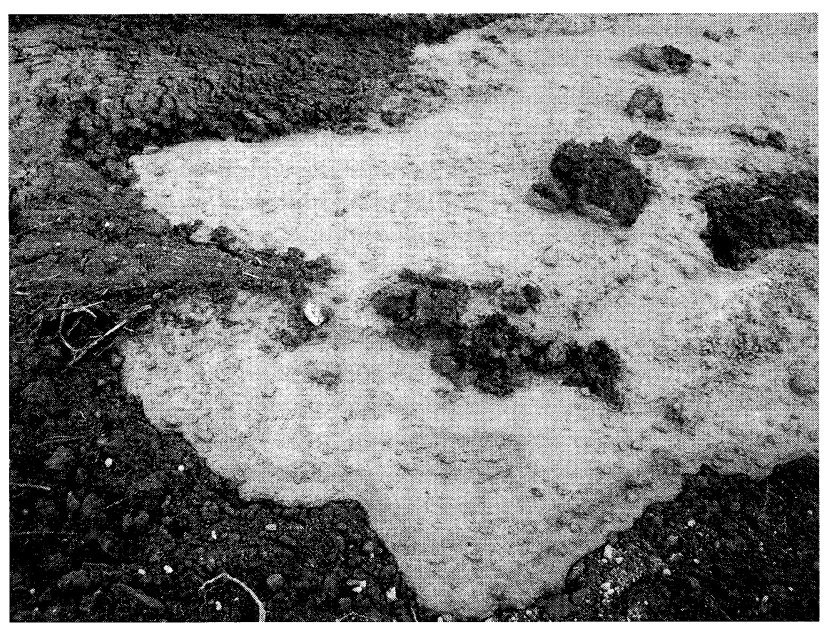

Photo 7. Fluidized collapsed soil by traveling of heavy machines on May 28

line was about $6-7 \mathrm{~m} / \mathrm{s}$ based on kinematic analyses of traces of mud splashes. Moreover, these evidences indicated that the landslide occurred during or immediately after the principle motion of the earthquake. Furthermore, the first evidence that the slide snaked down was supported by the observation of traces of mud splashes on the trees along both sides of the slide.

Flattened collapsed soil spread on a rice field at the downstream side of the slide. Photo 5 shows a collapsed soil deposit, flushed electronic poles, and sewage pipes on the west side on the rice field. Photo 6 also shows a collapsed soil deposit at the downstream side of the landslide on the east side on the rice field. Flushed bamboo remain standing and pumice deposit flown out from the slide are visible in the lower part of the photo. Traces of mud splashes were observed on the bamboo on a rice field. Figure 4 summarizes the results of field measurements of the collapsed soil on the rice field. The flattened spread collapsed soil had a small residual strength.

It was easily observed that the collapsed soil had potentially high fluidity even though the surface soil looked dry. Photo 7 shows fluidized soil flushed out of the collapsed soil after traveling of heavy construction machines. The fluidized collapsed soil seemed to behave similarly to high-fluidity concrete. Even cyclic jumping by a man caused fluidization of the collapsed soil under the feet. It is noteworthy that the collapsed soil fluidized easily with cyclic shear. It is possible that the loose structure of the filled pyroclastic sediments was attributable to insufficient compaction during filling.

\section{Physical Properties of the Filled Soil}

Table 1 summarizes results of physical tests for samples; the grain distribution is presented in Fig. 5. Locations of sampling sites from the uppermost area of the scarp to the landslide toe are shown in Fig. 4. Similar grain distributions were obtained at all sites: gravel-about $20 \%$; sand-about $50 \%$; silt-about $20 \%$, and clay-about $10 \%$. Nevertheless, all of the gravel was pumice. These results suggest that these samples consist 
Table 1. Summary of physical properties for samples at Dateshita landslide (Refer to Fig. 4 for the locations of the sampling sites)

\begin{tabular}{|c|c|c|c|c|c|c|c|c|c|c|}
\hline Sampling site & A & B & $\mathrm{C}$ & $\mathrm{D}$ & $\mathrm{E}$ & $\mathrm{F}$ & G & $\mathrm{H}$ & $I^{3)}$ & $\mathrm{J}^{3)}$ \\
\hline Sampling method & Disturbed & Undisturbed & Disturbed & Disturbed & Undisturbed & Disturbed & Disturbed & Disturbed & Disturbed & Block \\
\hline$w_{\mathrm{n}}(\%)$ & 26.1 & 28.0 & 30.6 & 55.7 & 38.6 & 31.8 & 40.9 & 42.6 & 39.1 & 29.8 \\
\hline$G_{\mathrm{s}}$ & 2.478 & - & 2.400 & 2.313 & - & 2.438 & 2.428 & 2.442 & 2.354 & 2.447 \\
\hline Gravel content (\%) & 17 & - & 18 & 15 & - & 17 & 18 & - & 20 & 14 \\
\hline Silt content (\%) & 22 & - & 23 & 23 & - & 20 & 20 & - & 24 & 25 \\
\hline Clay content $(\%)$ & 8 & - & 9 & 8 & - & 10 & 12 & - & 8 & 8 \\
\hline$e$ & - & $1.175^{1)}$ & - & - & $0.909^{2)}$ & - & - & 1.159 & 1.098 & - \\
\hline$\gamma_{\mathrm{t}}\left(\mathrm{kN} / \mathrm{m}^{3}\right)$ & - & 14.30 & - & - & 17.36 & - & - & 15.82 & 15.30 & - \\
\hline$S_{\mathrm{r}}(\%)$ & - & $59.0^{1)}$ & - & - & $103.6^{2)}$ & - & - & 89.8 & 83.8 & - \\
\hline
\end{tabular}

Notes: 1) using $\rho_{\mathrm{s}}$ at the site $\mathrm{A}, 2$ ) using $\rho_{\mathrm{s}}$ at the site $\mathrm{F}, 3$ ) after vibration of the samples.

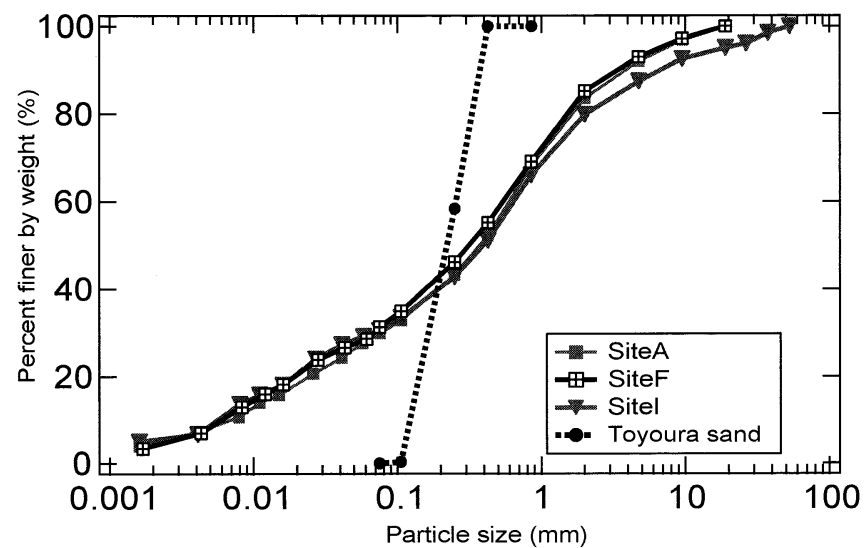

Fig. 5. Grain size distributions of collapsed soil at Dateshita landslide and Toyoura sand (Refer to Fig. 4 for the locations of the sampling sites)

of the same original soil. Regarding soil classification, it was categorized as silty sand with pumice.

The specific gravity of soil particles was 2.31-2.48, smaller than that of ordinary sand. The natural water contents of $26-56 \%$ were very high, as shown in Table 1. These features are attributable to the porous microstructures of pumice, as shown in Photo 8 taken by scanning electron microscope (SEM) with $2,000 \times$ magnification. The soil particle has potentially high water-absorbing capacity. In fact, after a dry sample was misted with water, the water content of the soil became greater $40 \%$. In the tests, the soil sample was dried outside until the initial water content was about $1 \%$. The dry density of the sample was $1.1 \mathrm{~g} / \mathrm{cm}^{3}$, which corresponded to that of undisturbed samples. In addition, it is noteworthy that the degree of saturation of fluidized soil (sampling at the site of $\mathrm{H}$ and I as shown in Table 1) was about $90 \%$; the fluidized soil was not completely saturated.

\section{Mechanical Properties of the Filled Soil}

Clarifying moisture characteristics of soil consisting of

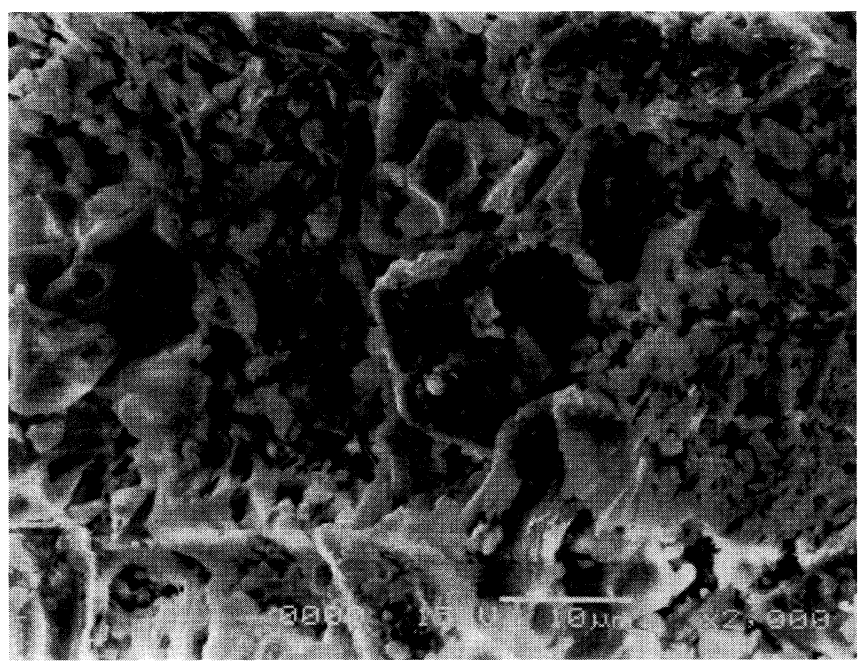

Photo 8. Microstructure of pumice by SEM $(\times 2,000$ magnifications $)$

porous particles like pumice is an important step in considering the unsaturated strength of collapsed soil. Figure 6 shows the relationship between suction and water content for the collapsed soil. The results for Toyoura sand and artificial sand are also shown for comparison. The artificial sand has the same distribution of grain size as Dateshita soil, and consists of some different soils such as Toyoura sand, kaolin clay, DL clay, and Keisa sand. These relations were obtained from water retention tests based on the JGS 0151-2000. A soil specimen was installed on a pedestal made of a ceramic disc with the air entry value of $300 \mathrm{kPa}$ in the cell. The specimen was $20 \mathrm{~mm}$ in height and $105 \mathrm{~mm}$. The suction of collapsed soil was much larger than those of the Toyoura sand and artificial sand in the partially saturated region. These results clearly show that Dateshita soil with porous pumice has high water retention capacity. Moreover, the suction of unsaturated collapsed soil could vanish with slightly increased water content; the relation had hysteretic characteristics. It is possible that even 


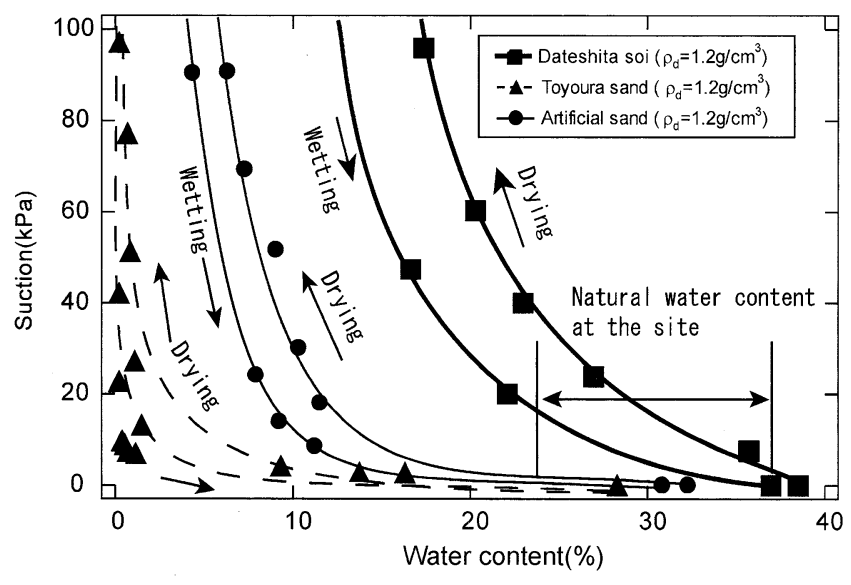

Fig. 6. Relations between suction and water content for collapsed soil at Dateshita landslide and Toyoura sand

loose unsaturated fill could remain stable because of the high suction. We require further investigation on moisture characteristics to clarify the unsaturated strength of the collapsed soil.

Kokusho et al. (2004) conducted undrained triaxial tests with undisturbed samples under a saturated condition. The dry density of the material was $1.04 \mathrm{~g} / \mathrm{cm}^{3}$, almost identical to that of unsaturated one, as shown in Table 1. They reported that the cyclic shear strength ratio was 0.19 under the conditions of $D A=5 \%$ and $N$ (number of cycles $)=20$. The residual deviator strength $\left(q=s_{1}\right.$ $-s_{3}$ ) after cyclic histories was $10 \mathrm{kPa}$, which was about $20 \%$ of undrained peak strength without cyclic history. Cyclic deformation behavior and post-cyclic behavior with unsaturated samples should be discussed for further investigation.

\section{Summary and Possible Mechanism of the Slide}

Based on the field investigation and laboratory tests, the features of the Dateshita landslide are summarized as follows:

1) The subsurface soil of the gentle slope with the angle of about $7^{\circ}$ was a fill with pyroclastic sediments, pumice tuff.

2) It had not rained for a week before the earthquake. Therefore, the upper part of the collapsed layer was unsaturated to a few meters' depth. The lower part was possibly saturated before the earthquake.

3) The fill structure was very loose, but the unsaturated soil remained stable with high suction.

4) The landslide occurred during or immediately after the principle earthquake motion.

5) The slide mass behaved as a mudflow with a small residual strength; the collapsed soil easily fluidizes with cyclic shear.

It is likely that the saturated fill liquefied during the earthquake. No strong motion was recorded close to the Dateshita landslide; however, " 5 upper" of JMA seismic intensity was recorded in Tsukidate town including the landslide. Moreover, the maximum horizontal acceleration of over 300 gal was recorded at other observation sites which were as far as the Dateshita landslide from the epicenter. Hence, the maximum horizontal acceleration at the surface was estimated as about 300 gal. This ground motion could easily induce liquefaction of the loose saturated fill. Moreover, it is possible that the unsaturated fill fluidized losing the initial shear strength during cyclic shear induced by the earthquake. If the unsaturated fill had retained its initial strength, the collapsed soil would not have spread on the rice field.

Volcanic soils, including pumice, generally crush their particles under the shear process (Miura et al., 2003). Particle crushing in the shear zone might cause high fluidity of the collapsed soil (Sassa, 1996). However, it remains unclear whether particle crushing of Dateshita soil occurs under the low overburden pressure with the depth of a few meters.

Earthquake-induced landslides of pyroclastic sediments similar to the Dateshita landslide were often recorded in past earthquakes as follows: embankment failures in Hachinohe during the 1968 Tokachioki earthquake (Mishima and Kimura, 1970), slope failure of residential filled ground in Shiraishi during the 1978 Miyagiken-oki earthquake (Kawakami et al., 1978), large scale debris flow at Mt. Ontake during the 1984 Naganoken-seibu earthquake (Kawakami et al., 1985) and the Las Colinas landslide during the $2001 \mathrm{El}$ Salvador earthquake (Konagai et al., 2002). Further investigation is required along with more strategic laboratory tests and solving the boundary problems, to determine the landslide mechanism.

\section{LANDSLIDE AT NISHISARUTA, KANAN-CHO DURING THE JULY 262003 EARTHQUAKE}

\section{Slide Overview}

During the 726 Eq., a landslide with a similar magnitude and configuration to Dateshita landslide during 526 Eq. occurred after the main shock at Nishisaruta, Kanancho, as shown in Photo 2. The Nishisaruta landslide was a large landslide induced by the $726 \mathrm{Eq}$. The Nishisaruta landslide was very close to the source area of the earthquake, as shown in Fig. 1. Although the original slope angle was steeper than that of Dateshita landslide, the average slope angle was less than $30^{\circ}$. The collapsed portion was about $30 \mathrm{~m}$ wide and $30-50 \mathrm{~m}$ long, with a depth of about $5 \mathrm{~m}$. It deposited about 20-30 m wide and $60 \mathrm{~m}$ long at the downstream side. The volume of the collapsed soil was estimated to be about $3,000 \mathrm{~m}^{3}$. The uppermost scarp of the collapsed slope was about $20 \mathrm{~m}$ high and $150 \mathrm{~m}$ long from the lowermost deposits at a rice field. The flow of collapsed soil stopped upon touching a narrow road over the rice field. The slide fortunately destroyed no structures and resulted in no deaths.

\section{Site Geology and Topography}

The surface soil of a hill behind the slide consists mainly of a cross-bedded, medium to coarse sandstone or conglomerate at the Miocene. Flattening the top of the hill, farmers made a rice field on the hill in the 1960s. The 


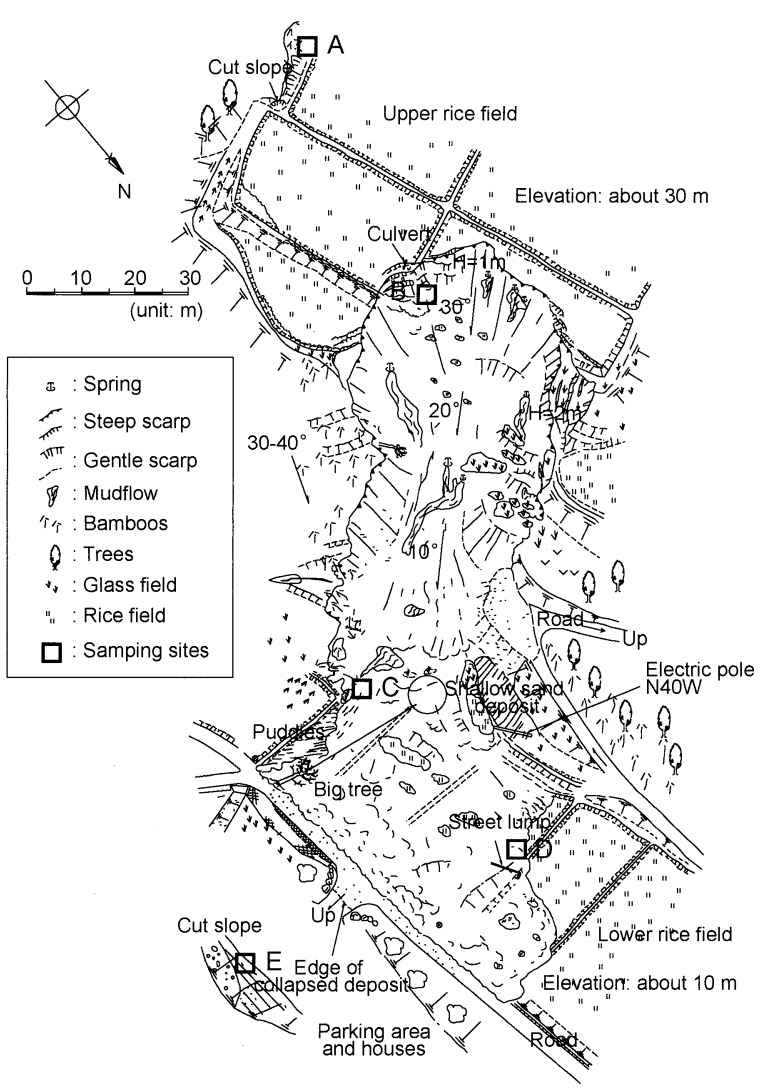

Fig. 7. Topography and collapsed configuration of Nishisaruta landslide (courtesy of Tohoku branch, OYO Corporation)

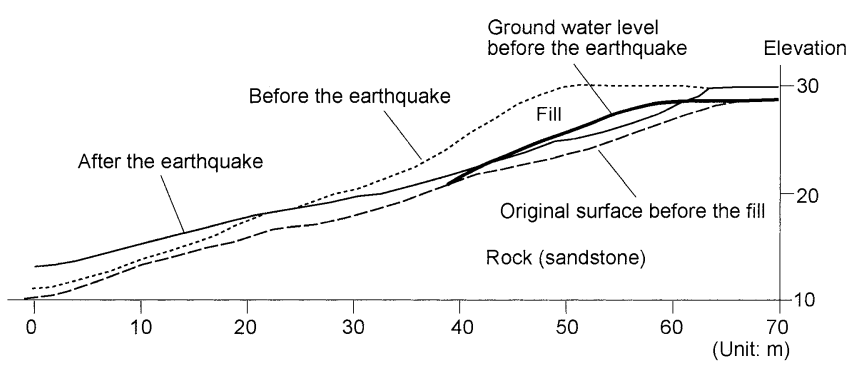

Fig. 8. Cross section and soil profiles of Nishisaruta landslide

collapsed area is located on a fill where the excavated hilltop sediments were pushed into a valley at the original topography. The slope structure closely resembles the Dateshita landslide.

Figure 7 shows a sketch of the collapsed configuration of the site. The longitudinal cross section at the centerline of the slide is also shown in Fig. 8. The configuration of the original topography estimated with the results of sounding tests (Irasawa et al., 2003) is also depicted in Fig. 8. The main failure was estimated to be a rotational slip at the upper part, higher than $10 \mathrm{~m}$. The slope angle at the upper collapsed part gradually changed from about $30^{\circ}$ to $20^{\circ}$. Then, the mass of soil detached from the upper portion and moved down along the original slope. It spread with the high water content on the rice field. The debris carried some trees, originally on the toe of the

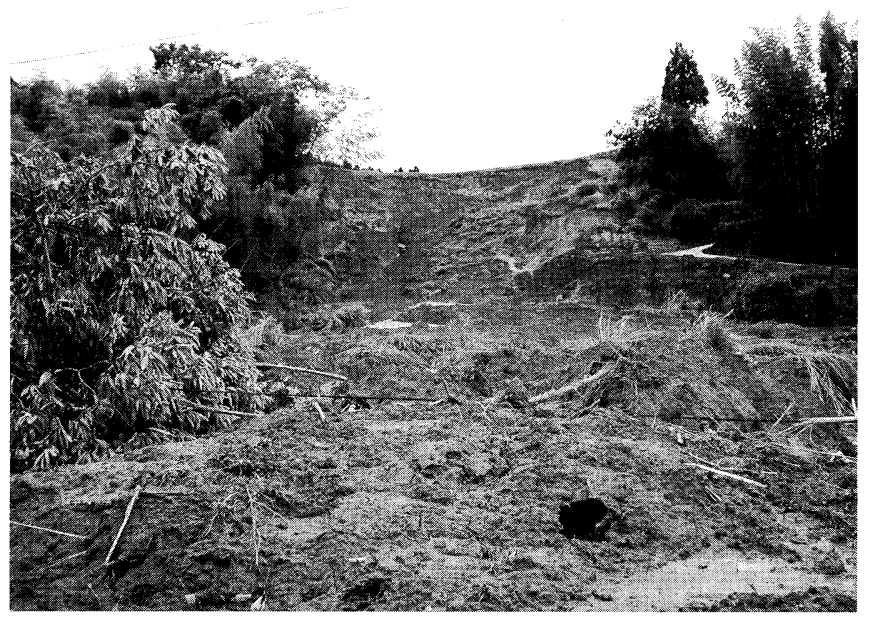

Photo 9. Flushed trees and scarp of Nishisaruta landslide on July 28 (courtesy of Techno Hase Co., Ltd.)

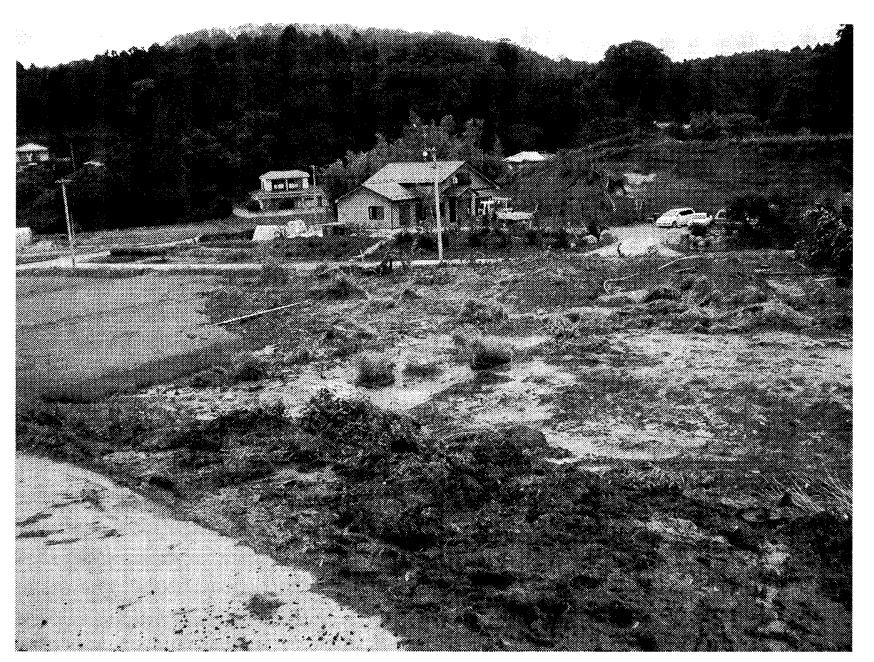

Photo 10. Deposit of collapsed soil on lower rice field of Nishisaruta landslide on July 28 (courtesy of Techno Hase Co., Ltd.)

original slope, near the narrow road with a traveling distance of about $30 \mathrm{~m}$, as shown in Fig. 7 and Photo 9. Although the large slide occurred after the main shock, a small slide occurred during the aftershock at 16:56 on the same day around the right side of the scarp in Fig. 7.

\section{Detailed Features and Possible Motion of the Slide}

Rainfall was one important feature at the Nishisaruta landslide, but no rainfall had been observed for a week before the Dateshita landslide, Tsukidate. It had rained for a week since July 23 in northern Miyagi. The accumulated precipitations of $114 \mathrm{~mm}$ before the earthquake were measured for 3 days. The 24-hour precipitation was estimated as $27 \mathrm{~mm}$, which was about one-tenth of the maximum records at the nearest observation site, Kashimadai. The rainfall infiltration made the collapsed fill wet, whereas little water was in the rice field on the hill. Some springs were actually observed on the scarp, as shown in Fig. 7. The ground water height estimated by 
the spring locations is also depicted in Fig. 8. In addition, the continuous rainfall helped the collapsed soil deposit on the slope and lower rice field to retain high water content after the failure. In fact, the deposit was soft with the high water content, as shown in Photo 10.

Some extensive cracks on the upper rice field were behind the scarp, as shown in Photo 11. These cracks were running parallel to the edge of the hill. If these cracks were opened during the foreshock, 7 hours before the main shock, rainwater could hare easily infiltrated through the cracks into the ground. This influence could raise the ground water table in the fill.

It is noteworthy that the Nishisaruta landslide occurred a few minutes after the principle motion of the main shock, whereas the Dateshita landslide occurred during or immediately after the principle motion. A witness who lived in the lowest house in Photo 2 described the experience as: "I felt large vertical vibration during the earthquake in the morning. Holding my baby, I got out my house with my grandfather. I intended to go to the car

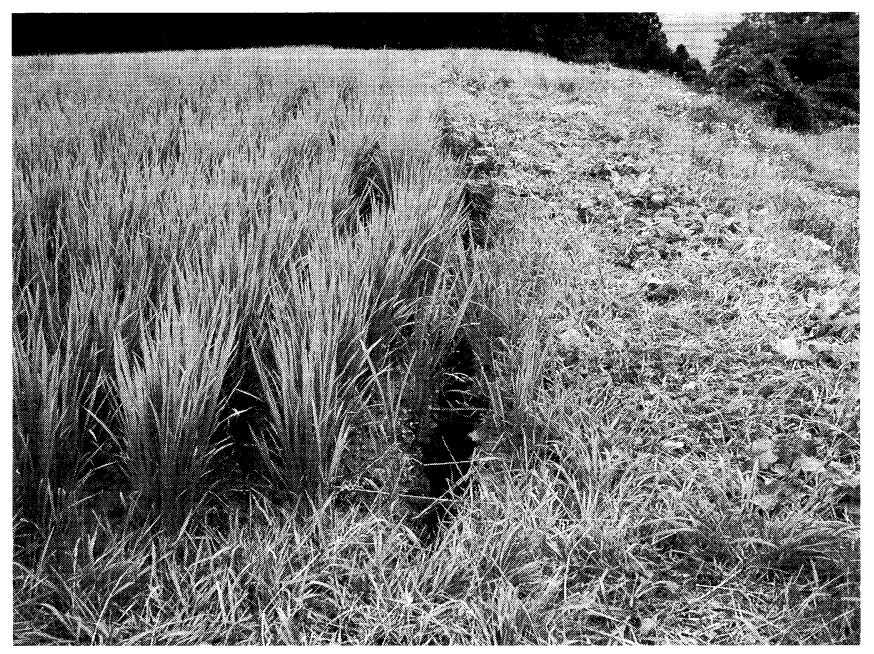

Photo 11. Extensive cracks on upper rice field behind the scarp of Nishisaruta landslide on July 28 (courtesy of Techno Hase Co., Ltd.) in my garage (next to the house). When we were getting in the car, the hill suddenly failed. It took a few minutes after the large vibration had passed. The slide reached the stone walls of the house in $60-120$ seconds. Trees at the toe of the slope that had moved with the landslide remained standing. After witnessing the landslide, we returned to our house. After the earthquake in the evening (the largest aftershock), the right side of the scarp failed; young rice plants were spread on the collapsed soil along the slope." This evidence clarifies that the slide occurred a few minutes after the principle motion of the main shock. Furthermore, the slide seemed to have travelled a distance of about $100-150 \mathrm{~m}$ in about $60-120$ seconds. Therefore, the average velocity was slightly slower than that of the Dateshita landslide.

\section{Physical and Mechanical Properties of the Filled Soil}

Some disturbed and undisturbed samples were taken at the sites as shown in Fig. 7. Table 2 summarizes the results of physical tests for the samples. The grain distribution of the sample at site B is presented in Fig. 9. Similar distributions were obtained at the fill sites of B, C, and D: gravel-about 10\%; sand-about 55\%; silt-about $15 \%$; and clay-about $20 \%$. These results suggest that these samples consist of the original soil, weathered sandstone, or conglomerate. Regarding soil

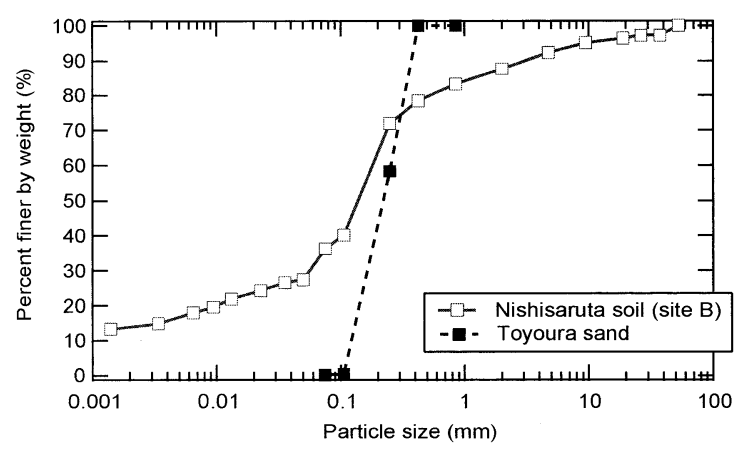

Fig. 9. Grain size distributions of collapsed soil at Nishisaruta landslide (Refer to Fig. 7 for the locations of the sampling sites)

Table 2. Summary of physical properties for samples at Nishisaruta landslide (Refer to Fig. 7 for the locations of the sampling sites)

\begin{tabular}{|c|c|c|c|c|c|c|}
\hline \multicolumn{2}{|l|}{ Sampling site } & $\underset{\text { Disturbed }}{\text { A }}$ & $\frac{B}{\text { Undisturbed }}$ & $\underset{\text { Disturbed }}{\mathrm{C}}$ & $\underset{\text { Disturbed }}{\mathrm{D}}$ & $\underset{\text { Disturbed }}{E}$ \\
\hline Specific gravity of soil particles & $G_{\mathrm{s}}$ & 2.700 & 2.710 & 2.709 & 2.699 & 2.752 \\
\hline Gravel contents & $(\%)$ & 0 & 13 & 12 & 4 & 0 \\
\hline Sand contens & $(\%)$ & 76 & 51 & 64 & 49 & 81 \\
\hline Silt contents & $(\%)$ & 8 & 21 & 12 & 22 & 8 \\
\hline Clay contents & $(\%)$ & 16 & 15 & 12 & 25 & 11 \\
\hline Maximum particle size & $D_{\max }(\mathrm{mm})$ & 4.75 & - & - & 19 & 4.75 \\
\hline Liquid limit & $w_{\mathrm{L}}(\%)$ & - & - & 38.5 & - & - \\
\hline Plastic limit & $w_{\mathrm{P}}(\%)$ & - & - & 24.7 & - & - \\
\hline Plasticity index & $I_{\mathrm{P}}(\%)$ & - & - & 13.8 & - & - \\
\hline Natural water contents & $w_{\mathrm{n}}(\%)$ & - & 32.1 & 28.8 & - & - \\
\hline
\end{tabular}


classification, the soil was categorized as fine-graded sand.

Table 3 summarizes results of physical and mechanical tests for undisturbed samples. Undisturbed samples were taken by block sampling method at the uppermost scarp, the site B in Fig. 7, where the fill was considered to remain stable. Parameters in Table 3 were obtained by the following laboratory tests with the undisturbed samples: density tests, permeability tests, isotropic consolidation tests, CD tests, stress-controlled undrained cyclic shear tests with constant stress amplitudes, and strain-controlled undrained cyclic shear tests with gradually increasing strain amplitude. Shear tests were performed with a conventional triaxial test apparatus.

Next we will address cyclic undrained deformation behavior. Figure 10 shows the cyclic stress-strain relation and the effective stress path obtained from stresscontrolled cyclic shear tests with shear stress ratio of 0.3 . Test samples were consolidated isotropically: the initial effective stress was $50 \mathrm{kPa}$, and the $B$ value was 0.84 . We could not achieve the sufficient $B$ value of 0.95 with standard method because the soil sample contained a significant amount of fine contents. However, we adopted the $B$ value of 0.84 in this study because the liquefaction

Table 3. Summary of physical and mechanical properties for undisturbed samples at Nishisaruta landslide

\begin{tabular}{ll|c}
\hline Dry density & $\rho_{\mathrm{d}}\left(\mathrm{g} / \mathrm{cm}^{3}\right)$ & 1.35 \\
\hline Wet density & $\rho_{\text {sat }}\left(\mathrm{g} / \mathrm{cm}^{3}\right)$ & 1.78 \\
\hline Water content $(\%)$ & $w(\%)$ & 32.1 \\
\hline Specific gravity & $G_{\mathrm{s}}$ & 2.71 \\
\hline Void raio & $e$ & 1.01 \\
\hline Coefficient of permeability at $20^{\circ} \mathrm{C}$ & $k(\mathrm{~cm} / \mathrm{s})$ & $9.2 \times 10^{-7}$ \\
\hline Compression index & $\lambda$ & $1.42 \times 10^{-2}$ \\
\hline Swelling index & $\kappa$ & $6.27 \times 10^{-3}$ \\
\hline Initial shear modulus & $G_{0}(\mathrm{kPa})$ & $7.65 \times 10^{4}$ \\
\hline Internal friction angle & $\phi_{\mathrm{f}}(\mathrm{degree})$ & 43.8 \\
\hline Phase transformation angle & $\phi_{\mathrm{p}}(\mathrm{degree})$ & 26.0 \\
\hline Cyclic shear stress ratio $(N=20, D A=5 \%)$ & $\mathrm{CSR}$ & 0.34 \\
\hline
\end{tabular}

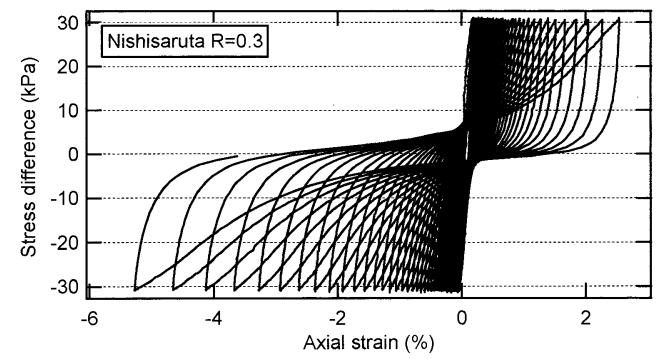

(a) stress strain relation strength with the $B$ value of about 0.8 was almost same as that with the $B$ value of 0.95 (Tsukamoto et al., 2002). The mean effective stress gradually decreased with the increase of the cycles and finally liquefied, but the $B$ value was not sufficiently large. After the mean effective stress became almost zero, cyclic mobility, recovering the shear stiffness, was observed. These behaviors reflected normal cyclic behavior of fine-graded sand.

Kokusho et al. (2004) conducted undrained triaxial tests with undisturbed samples under saturated conditions. The initial void ratio and fine contents of the material were about 1.0 and $20 \%$, respectively. The initial void ratio was almost the same value as that shown in Table 2. However, the fine contents were slightly less than that of the sample in Fig. 9 in this study. It is reported that the cyclic shear strength ratio was 0.22 , which is smaller than 0.34 in Table 3, under the conditions: the confining pressure of $49 \mathrm{kPa}, D A=5 \%$ and $N=20$. The discrepancy was attributable to the different fine contents.

\section{Discussion on Slope Stability with Numerical Analysis}

Preliminary effective stress analyses were performed to discuss time-dependent stability of the collapsed slope. We investigated the influence of the foreshock on the slope stability using not only the main shock but also the foreshock for the input motion. A two-dimensional soilwater coupled problem was formulated based on a $u-p$ formulation (Oka et al., 1994). The constitutive equation used for sand was an elasto-plastic kinematic hardening model (Oka et al., 1999).

A finite element model of the slope in Fig. 11 was prepared based on the configuration shown in Fig. 9. Table 4 shows the parameters of models for each layer. A linear elastic model was used for the rock-base ground, which was assumed to be stiff and stable. The shear wave velocity was assumed to be $2,000 \mathrm{~m} / \mathrm{s}$. The RambergOsgood (R-O) model was used for the unsaturated fill above the water table that was assumed not to be liquefiable. Parameters of R-O model were determined based on the results of $\mathrm{CD}$ tests and cyclic strain-controlled shear tests. The cyclic elasto-plastic model was used for the fill below the water table, which was assumed to be liquefiable soil. A detailed description of the parameters of the

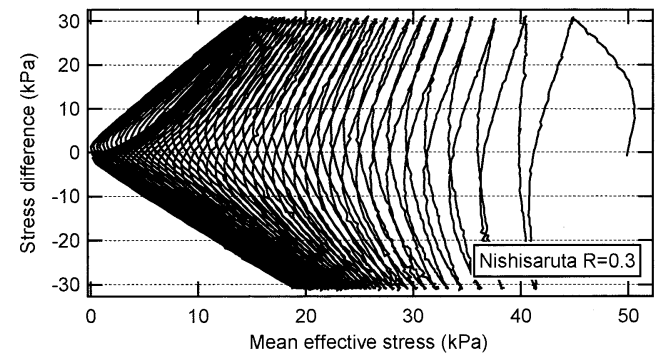

(b) effective stress path

Fig. 10. Cyclic behavior of collapsed soil at Nishisaruta landslide 
Table 4. Material parameters of the constitutive models for each layer

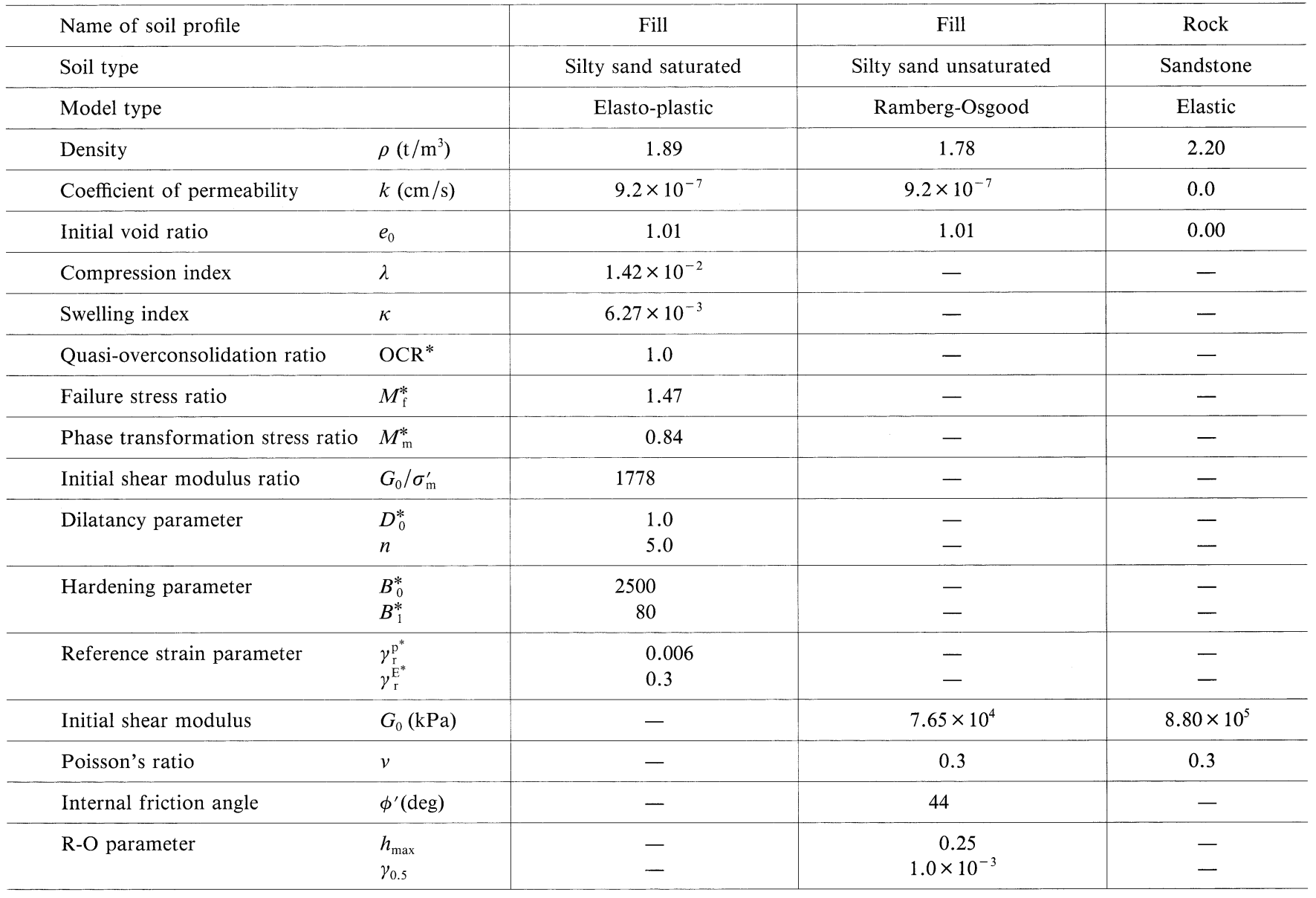

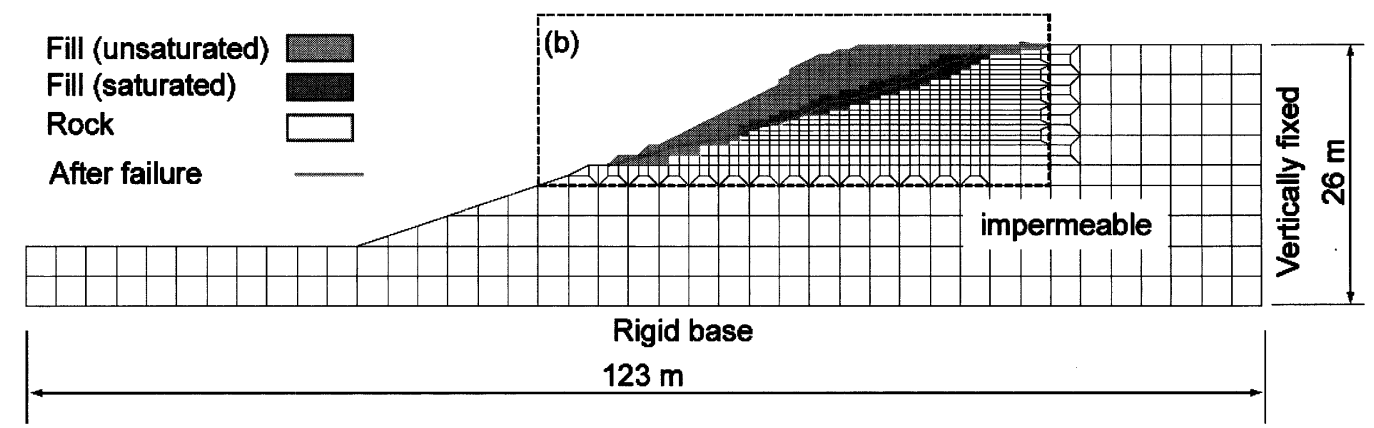

(a) whole view

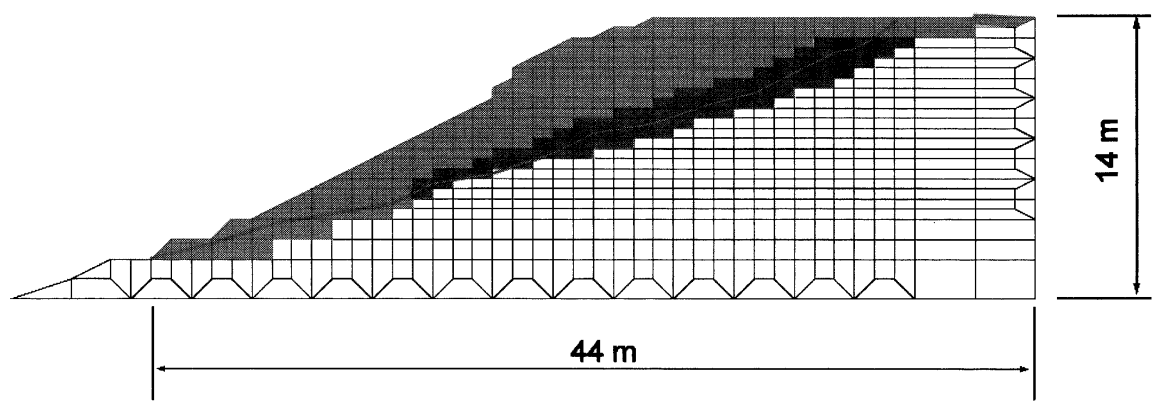

(b) filled area

Fig. 11. Finite element model of Nishisaruta landslide 


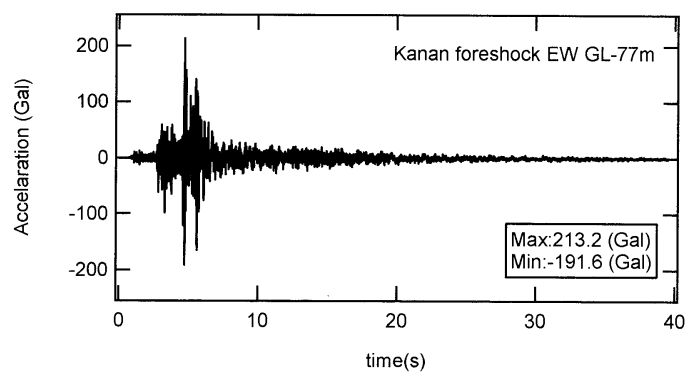

(a) foreshock at 0:13

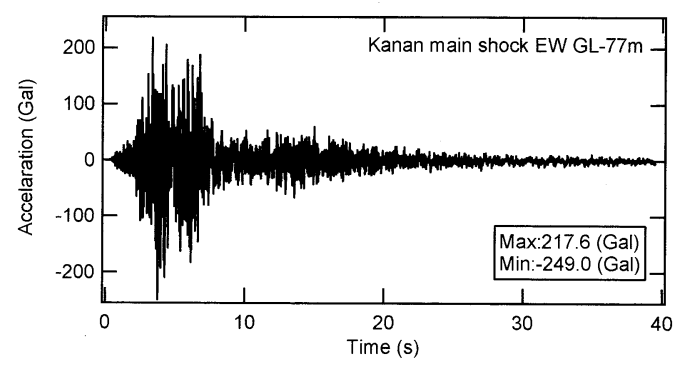

(b) main shock at 7:26

Fig. 12. Time histories of input acceleration (MLIT, 2003)

cyclic elasto-plastic model can be referred to the corresponding reference (Oka et al., 1999). The following parameters, $e_{0}, \lambda, \kappa, \mathrm{OCR}^{*}, M_{\mathrm{m}}^{*}, M_{\mathrm{f}}^{*}$, and $G_{0} / \sigma_{\mathrm{m}}^{\prime}$ were determined directly by physical property tests, isotropic consolidation tests, CD tests, and strain-controlled undrained cyclic shear tests. In principle, although the remaining parameters could be determined directly by special laboratory tests, the data adjusting method is more practical to determine the soil parameters. Values of material parameters are selected to provide a good description of the stress-strain relations and effective stress paths under cyclic loading conditions and liquefaction strength curves obtained by stress-controlled cyclic undrained shear tests. The liquefaction strength, shown in Table 3, was used for the target. Although the liquefaction strength might not be appropriate for a completely saturated fill, it remained unclear whether the fill was completely saturated under the condition with precipitations of $114 \mathrm{~mm}$ because it contained fine contents of about $30 \%$.

Regarding the deformation boundary condition, the bottom of the model was set to be rigid. Lateral boundaries were set to be fixed only in the vertical direction. Time histories of input acceleration for the foreshock and main shock as shown in Fig. 12 (MILT, 2003) were set at the rigid bottom boundary. These acceleration records were EW components observed at the depth of GL-77 m at the Kanan site, which was located about $10 \mathrm{~km}$ from the slide. The site was one of the nearest observation sites to the slide. However, these acceleration records might not be appropriate for real records at the slide because the locality of ground response is often predominant during the shallow earthquake. Input acceleration records at the slide shall be investigated for more precise analysis. Regarding the drainage boundary condition, the lateral and bottom boundaries were presumed to be impermeable, whereas the water table was permeable. Elements of the unsaturated fill above the water table were treated as dry elements without degrees of freedom of pore water pressure.

The initial stress state was computed by the static drained analysis, which the gravity force was loaded to the whole model. After the dynamic analysis for the foreshock, static analysis with seepage was performed until the main shock.

Other numerical conditions are summarized as follows. A time integration step of 0.001 seconds was adopted to ensure numerical stability. Hysteresis damping by the constitutive model was basically used, and Rayleigh damping proportional to initial stiffness was used to describe damping, especially in the high frequency domain. The factor of Rayleigh damping was set empirically to be 0.003 . In addition, $\beta$ and $\gamma$ in the Newmark method were set to be 0.3025 and 0.6 , respectively, to ensure numerical stability.

First, response values of fill elements are discussed. Figure 13 shows distributions of excess pore pressure ratios at four times: immediately after the foreshock, just prior to the main shock, immediately after the main shock, and 15 minutes after the main shock. The excess pore water ratio was defined as normalized excess pore water pressure by the initial effective overburden pressure in this study. Although complete liquefaction did not occur throughout the entire area of saturated fill after the foreshock, high excess pore pressure was generated in some upper elements in the saturated fill. Immediately prior to the main shock, about 7 hours after the foreshock, the excess pore water pressure did not completely dissipate in upper elements of the saturated fill. After the main shock, the excess pore water pressure in the saturated fill rose again.

Secondly, time-dependent slope stability along the failure surface is discussed. Figure 14 shows time histories of safety factors along the failure surface during the foreshock and main shock. The safety factor was calculated by $\Sigma \tau_{\mathrm{f}} / \Sigma \tau$, where $\Sigma$ summates shear strength and shear stress for all elements along the surface after the earthquake. The safety factor without the foreshock is also depicted in Fig. 14(b). The foreshock demonstrably affected the slope stability. Hence, the residual excess pore water pressure induced by the foreshock should be taken into account in stability analyses. Moreover, the slope stability was gradually lost during the main shock because of the buildup of pore water pressure in the fill. These results qualitatively supports that the Nishisaruta landslide which occurred a few minutes after the principal motion of main shock. However, the safety factor became less than one at about 10 seconds for the analysis 


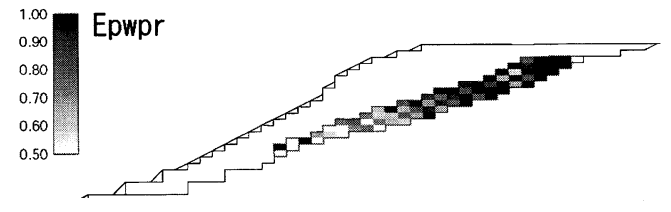

(a) immediately after the foreshock

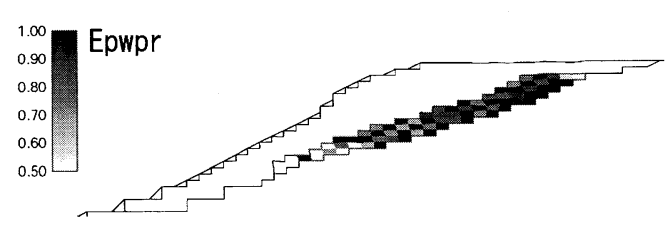

(c) immediately after the main shock

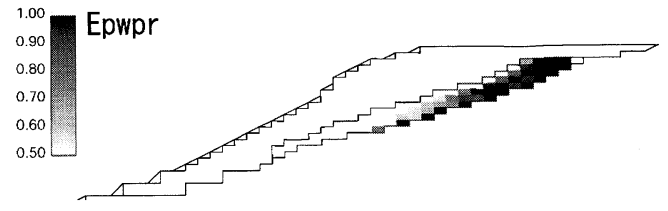

(b) just prior to the main shock

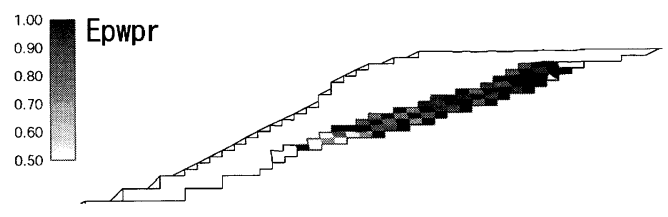

(d) 15 minutes after the main shock

Fig. 13. Distributions of excess pore water pressure

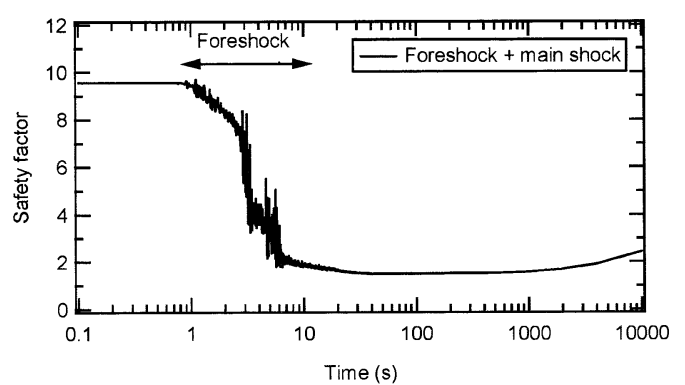

(a) during the foreshock

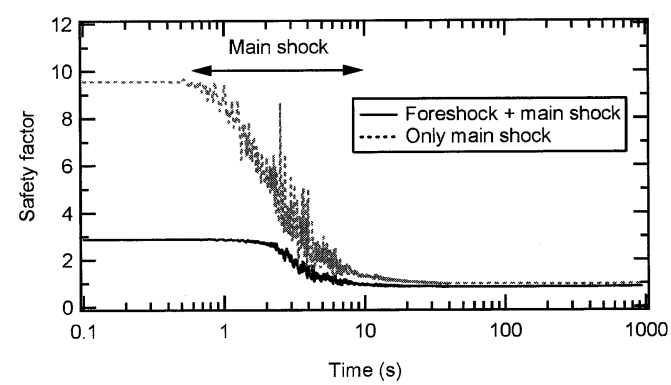

(b) during the main shock

Fig. 14. Time histories of safety factor along the failure surface

with the foreshock, which was much earlier than the real failure time. More careful simulation with precise material properties and input motions is required to reproduce the actual failure time. In particular, we need careful modeling of the unsaturated zone to reproduce the delayed failure after the main shock.

\section{Summary and Possible Mechanism of the Slide}

Based on field investigation, laboratory tests and numerical simulations, features of the Nishisaruta landslide are summarized as follows:

1) The subsurface soil of the slope was a fill with finegraded sand, which originated from sandstone on the hill.

2) The main failure of the slide occurred at the upper part of the slope. The slope angle at the collapsed part gradually changed from about $30^{\circ}$ to $20^{\circ}$.

3) The mass of soil detached from the upper portion moved down along the original slope, and spread with high water contents on the lower rice field.

4) It is possible that the rainfall with the precipitations of $114 \mathrm{~mm}$ for three days before the earthquake made the collapsed fill wet.

5) The landslide occurred a few minutes after the principle motion of the main shock.

6) Numerical simulations suggested that the saturated fill liquefied during the main shock. In addition, the residual excess pore pressure induced by the foreshock affected the slope stability.

It is likely that the fill liquefied during the earthquake. The upper portion of the fill lost shear strength because of liquefaction during movement down the slope; it spread on the lower rice field. The residual strength, after undrained cyclic shear loading, of the collapsed soil was much larger than that of the collapsed soil at Dateshita (Kokusho et al., 2004). Therefore, the inertial force attributable to the steeper slope angle was possible in allowing the detached soil to spread widely.

\section{CONCLUDING REMARKS}

We conducted site investigation for two major landslides, Dateshita landslide, Tsukidate-cho during the 526 Eq. and Nishisaruta landslide, Kanan-cho during the 726 Eq. In addition, physical and mechanical soil tests and preliminary numerical simulations were performed. We summarized the results as follows.

The Dateshita landslide was a large landslide induced by the $526 \mathrm{Eq}$. The subsurface soil of the gentle slope with an angle of about $7^{\circ}$ was a fill with pyroclastic sediments, pumice tuff. The structure of the fill was very loose, but the unsaturated soil maintained stability with high 
suction. The landslide occurred during or immediately after the principle motion of the earthquake. The mass of the slide behaved like a mudflow, and the collapsed soil easily fluidized with cyclic shear. It is likely that the saturated fill liquefied during the earthquake because the maximum horizontal acceleration at the surface was estimated to about $300 \mathrm{gal}$. Moreover, it is possible that the unsaturated fill fluidized losing the initial shear strength during cyclic shear induced by the earthquake. We need to conduct further investigations, more strategic laboratory tests and solve the boundary problems, to determine the landslide mechanism.

During the 726 Eq., a landslide with similar magnitude and configuration to the Dateshita landslide occurred after the main shock at Nishisaruta, Kanan-cho. The Nishisaruta landslide was also one of the largest landslides induced by the $726 \mathrm{Eq}$. Some features were different from that of the Dateshita landslide. The Nishisaruta landslide was very close to the source area of the earthquake. For this reason, a larger seismic load affected the slope. The angle of the original slope (with the angle of $20^{\circ}-30^{\circ}$ ) was steeper than that of the Dateshita landslide. Rainfall was an important feature of the Nishisaruta landslide, whereas no rainfall was observed for a week before the Dateshita landslide. Moreover, the Nishisaruta landslide occurred a few minutes after the principle motion of main shock, whereas the Dateshita landslide occurred during or immediately after the principle motion.

The subsurface soil of the slope of the Nishisaruta landslide was a fill with fine-graded sand that originated from sandstone on the hill. The upper portion of the slope that lost its shear strength because of liquefaction moved down along the slope, and spread with high water contents on the lower rice field. It is possible that rainfall with precipitations of $114 \mathrm{~mm}$ for three days before the earthquake, moistened the collapsed fill. Numerical simulations suggested that the saturated fill liquefied during the main shock. In addition, the residual excess pore pressure induced by the foreshock affected the slope stability. We need more careful simulation with precise material properties and input motions for reproducing the real failure time.

\section{ACKNOWLEDGEMENTS}

The Japanese Geotechnical Society supported a part of the investigation. The members of the reconnaissance team on the earthquakes in the Japanese Geotechnical Society provided valuable information to the authors. In addition, Miyagi Prefectural Government and Techno Hase Co., Ltd. provided the plane and sectional topographic maps at the Dateshita site. Tohoku branch of OYO Corp. provided the plane topographic map at the Nishisaruta site. Kokusai Kogyo Co., Ltd. provided aerial photos of the sites. Dr. Motoyuki Ushiyama of Tohoku University provided valuable photos and suggestions regarding landslides. The National Institute for Land and Infrastructure Management, Ministry of Land,
Infrastructure and Transport, provided strong motion records of the July 262003 earthquake. Graduate and undergraduate students in the Geotechnical Laboratory, Tohoku University, were very helpful in the site investigations and laboratory tests. Mr. Satoshi Ichihashi, undergraduate student of Tohoku University, carried out the numerical simulations. The authors wish to express their deep gratitude to these people and organizations for their assistance.

\section{REFERENCES}

1) Irasawa, M., Ushiyama, M., Matsumura, K., Kawabe, H., Hiramatsu, S. and Higaki, D. (2003): Sediment-related disasters caused by earthquake in the offing the northern part of Miyagi prefecture in July, 2003 (prompt report), J. Jpn Society of Erosion Control Engineering, 56(3), 44-54 (in Japanese).

2) Kawakami, F., Asada, A. and Yanagisawa, E. (1978): Damage to embankments and earth structures due to Miyagiken-oki earthquake of 1978, Tsuchi-to-Kiso, JGS, 26(12), 25-32 (in Japanese).

3) Kawakami, H., Konishi, J. and Saitoh, Y. (1985): Mechanism of slope failures by the Naganoken-seibu earthquake 1984 and the characteristics of pumice, Tsuchi-to-Kiso, JGS, 33(11), 53-58 (in Japanese).

4) Kokusho, K., Hara, T., Tsutsumi, Y. and Hoshino, K. (2004): Mechanical soil properties in slope failure under seismic loading in Tsukidate-cho and Kanan-cho in Miyagi prefecture, Proc. 39th Jpn Nat. Conf. Geotech. Engrg., 2085-2086 (in Japanese).

5) Konagai, K. (2003): Slope failure at Tsukidate (Topography and configuration), Reconnaissance Report on the May 26, 2003, MIYAGIKEN NO OKI EARTHQUAKE, Joint Delegation Team with Japan Society of Civil Engineers and Japan Geotechnical Society, 9-10 (in Japanese).

6) Konagai, K., Johannson, J., Mayorca, P., Yamamoto, T., Miyajima, M., Uzuoka, R., Pulido, E. N., Duran, F. C., Sassa, K. and Fukuoka, H. (2002): Las Colinas landslide caused by the January 13, 2001 off the coast of El Salvador earthquake, J. Jpn Assoc. Earthquake Engineering, 2(1), 1-15.

7) Mishima, S. and Kimura, H. (1970): Characteristics of landslides and embankments failures during the Tokachioki earthquake, Soils and Foundations, 10(2), 39-51.

8) Miura, S., Yagi, K. and Asonuma, T. (2003): Deformationstrength evaluation of crushable volcanic soils by laboratory and in-situ testing, Soils and Foundations, 43(4), 47-58.

9) National Institute for Land and Infrastructure Management, Ministry of Land, Infrastructure and Transport (2003): Strong motion records at Kanan site during July 26, 2003.

10) Oka, F., Yashima, A., Shibata, T., Kato, M. and Uzuoka, R. (1994): FEM-FDM coupled liquefaction analysis of a porous soil using an elasto-plastic model, Applied Scientific Research, 52, 209-245.

11) Oka, F., Yashima, A., Tateishi, A., Taguchi, Y. and Yamashita, S. (1999): A cyclic elasto-plastic constitutive model for sand considering a plastic-strain dependence of the shear modulus, Geotechnique, 49, 661-680.

12) Sassa, K. (1996): Prediction of earthquake induced landslides, Special Lecture of 7th Int. Symp. Landslides, Balkema, Rotterdam, 1, 115-132.

13) Sassa, K., Fukuoka, H., Scarascia-Mugnozza, G. and Evans, S. (1996): Earthquake-induced-landslides: distribution, motion and mechanics, Special Issue on Geotechnical Aspects of the January 17, 1995 Hyogoken-Nambu Earthquake, Soils and Foundations, 53-64.

14) Tsukamoto, Y., Ishihara, K., Nakazawa, H., Kamada, K. and Huang, Y. (2002): Resistance of partly saturated sand to liquefaction with reference to longitudinal and shear wave velocities, Soils and Foundations, 42(6), 93-104. 